Roberts LM, Davis GK, Homer CSE. Pregnancy with gestational hypertension or preeclampsia: A qualitative exploration of women's experiences. Midwifery, 2017, 46 pp. $17-23$.

\title{
Pregnancy with gestational hypertension or preeclampsia: A qualitative exploration of women's experiences
}

\section{INTRODUCTION}

Hypertensive disorders of pregnancy (HDP) are the most common medical complication of pregnancy, affecting $10 \%$ of pregnant women worldwide (American College of Obstetricians and Gynecologists 2013; Roberts \& Gammill 2005). Hypertension may exist prior to pregnancy or develop during pregnancy. There are two pregnancy-specific hypertensive disorders: gestational hypertension $(\mathrm{GH})$ and preeclampsia (PE). By definition, $\mathrm{GH}$ is hypertension that develops after 20 weeks of pregnancy without any organ involvement and is a benign condition that usually has good maternal and fetal outcomes (Tranquilli et al. 2014). In PE, hypertension develops after 20 weeks gestation and is associated with at least one other organ involvement, most often the kidneys, but also liver, central nervous system, haematological system or the placenta (Tranquilli et al. 2014). Preeclampsia is a more significant disorder associated with increased rates of maternal and perinatal morbidity and mortality (Steegers et al. 2010).

Women who are diagnosed with $\mathrm{GH}$ or PE often require specialised care from a multidisciplinary team, antenatal hospital admissions, and a longer postnatal stay that may include time in an acute care setting such as an Intensive Care Unit (ICU). There are reports of the physical and psychological outcomes following pregnancy complicated by hypertension (Andersgaard et al. 2012; Anderson 2007; Bushnell \& Chireau 2011; Giguere et al. 2012; Williams 2011) and the long term health risks (Bellamy et al. 2007; McDonald et al. 2008), but there is scant research reporting on the woman's experience of HDP from her perspective, how she coped with it, and whether the care she received influenced her experience. 
One of the few studies specifically about the woman's experience of HDP explored the needs of women who had been admitted to hospital (Barlow, Hainsworth \& Thornton 2008). Interviewed within three days of antenatal admission, this study showed that women sought support from partners and family and valued the support from other women in the hospital ward as they seemed to have an intrinsic understanding of the situation. There was no subsequent follow-up so it is not clear how they coped over time.

In a study from the United Kingdom, women at the postnatal clinic interviewed after a pregnancy complicated by PE, were asked about their understanding of future health risks (Brown et al. 2013). Women were mostly concerned about the next pregnancy, especially the recurrence of the HDP, the health of the baby and a long hospital admission, rather than their own health.

In high income countries, women with HDP are usually well managed with prompt, appropriate and effective interventions (Furuta, Sandall \& Bick 2014). Despite this, some experience a life threatening event which may lead to psychological sequelae (Vincent 2006). This may impact adversely on mother-infant attachment and child development (Sharp et al. 1995) and their overall experience.

It is important to better understand the perspectives of women with HDP in order to enhance their quality of care and to improve their pregnancy and birth experience. The aim of this study was to explore women's experiences of a pregnancy complicated by either GH or PE using a qualitative approach, to appreciate the woman's perspective, how she coped with it psychologically, and whether the care she received influenced her experience.

\section{METHODS}

A qualitative descriptive study, as described by Sandelowski (2000), was undertaken. Qualitative descriptive methods are a useful form of enquiry when investigating previously unexamined experiences (Avis 2003; Sandelowski 2000) and afford a detailed understanding of important and sometimes complex situations (Sandelowski 2000). This approach enables life experiences to be explored in depth, and therefore gain insight and understanding of this experience from the participants' perspective (Vaismororadi, Turunen \& Bondas 2013). 
Ethical approval was granted by the Local Health District Human Research Ethics Committee, the hospital Governance Unit and the university.

\section{Setting}

The study was carried out at St George Hospital in Sydney, Australia, which caters for 2,500 births annually. The maternity unit is a regional referral metropolitan service where care can be provided to women and infants of medium to high risk (Centre for Epidemiology and Evidence 2016).

\section{Participants}

Women who were diagnosed with either GH or PE in their preceding pregnancy were purposefully recruited. Participants had previously consented to a five year follow-up study (Davis et al. 2016) being conducted at the hospital, and attended the hospital at six months postpartum for study measurements. Women initially met the researcher at recruitment in the immediate postpartum period, and again at the six month study visit. At the later visit, women were invited to participate in a face-toface interview about their pregnancy and birth experience. Women who agreed to participate were contacted again at 10 months postpartum to confirm willingness to consent and organise a convenient place and time for the interview.

In total, 37 women were approached and 35 agreed to be contacted again. Six women were unable to be contacted and three declined consent at the second contact. Data saturation, where no new information or concepts arose from the interviews, was reached by the twentieth interview so recruitment ended at that point. The remaining six women were contacted and thanked for their offer of participation.

\section{Data collection}

Ethical approval was granted by the Local Health District Human Research Ethics Committee, the hospital Governance Unit and the university.

Semi-structured face-to-face interviews were conducted at 10-12 months postpartum. The timing of the interview was in line with suggestions from both Bennett (1985) and Simkin (1992) who propose that interviewing between months 
later and up to two years following the birth gives a more accurate perspective of the woman's experience.

Interviews were conducted at a mutually agreeable private place where the woman felt comfortable to share her story; 17 at the woman's home and three in a private office at the hospital. Each interview lasted about 45 minutes. The first five interviews were conducted by two female midwives who had extensive knowledge and clinical experience in caring for women with HDP. One midwife had considerable experience in interviewing women. The last 15 interviews were conducted by one midwife (first author). A series of open-ended questions guided the interview with flexibility in the questioning to respond to the woman. The questions included:

How did you feel when you were told you had high blood pressure in your pregnancy?

How was your care from the midwives and doctors after you found out about your complication?

How did you feel after the birth?

How was your baby after the birth?

What worried you the most about having high blood pressure in your pregnancy?

Looking back, how do you feel about your pregnancy now?

All interviews were digitally recorded. Recordings were de- identified and transcribed verbatim by the main interviewing midwife within three to four days of the interview and later transferred to the software programme NVivo for coding.

\section{Data analysis}

Data analysis began after all interviews had been transcribed. Firstly, data were separated into sections such as pregnancy, birth, baby and postpartum. This process is described by Saldana (2013) as preparing the data, giving a greater familiarity with the contents before more detailed examination begins. The second stage, initial coding, was performed using NVivo. Line by line analysis was then 
undertaken and nodes, a collection of quotes about a specific area of interest (QSR International 2014), were created. Transcripts were reread and recoded to ensure that initial coding was accurate and all useful data were included. The final stage of analysis was performed by two researchers and themes were derived from the data codes. This thematic analysis was applied in order to describe different concepts in relation to the research question (Braun \& Clarke 2006). Sub-themes were grouped into main themes.

Direct quotes are provided to illustrate the themes. Numbers at the end of each quote have replaced names to protect the woman's identity and to show how different women had similar experiences.

\section{FINDINGS}

The women interviewed were aged between 20 and 40 years, 15 were first time mothers and the gestation at which they gave birth varied from 30 to 41 weeks (Table 1).

There were four main themes identified from the data: Reacting to the diagnosis, Challenges of being a mother, Processing and accepting the situation, and Moving on from the experience. Mediating factors that improved the experience were Feeling safe and trusting the care providers, Continuity of care and carer, and Valuing social support from partner, family and friends (Figure 1).

\section{Reacting to the diagnosis}

When women were informed of their diagnosis, they reacted by feeling surprised, scared or guilty. They described feeling unprepared and needed time to understand the significance of the diagnosis. This took time for all of them and often occurred well after the birth.

For some women, the diagnosis was unexpected. They said:

"I really don't know why it caused the blood pressure problem. I can't find out why, so I'm a bit surprised because I didn't have a blood pressure problem before" (20) 
"When they said it had turned into preeclampsia, it was all a bit shocking. I don't think I processed at all about how I felt about it" (7)

For three women, the diagnosis came as no surprise due to a family history of hypertension. They said:

"All my life I remember mum saying she had preeclampsia and blood pressure and she'd had Caesars [caesarean sections] because of the preeclampsia. I hadn't appreciated the genetic link to preeclampsia which I now know is obviously exceptionally strong. So when I got admitted it was like, well, mum had preeclampsia" (16)

"I didn't need to worry about it, people are a lot worse and they come through and that kind of kept me aware that, and my mother had it as well and my grandmother, so, l'd sort of expected it" (1)

"Both of my parents have hypertension so I was not very surprised that I had it. I was expecting that I would have high blood pressure but I did not expect that it was going to be that bad" (3) DELETE THIS QUOTE

Many women felt scared of the potential dangers such as having a stroke or their baby dying, and of not knowing that something could be wrong. For example:

"You have that fear but you don't want to think about it or linger on that, you just want to make sure that baby's OK and you're OK. Just hope things go well" (4)

"It's a bit scary. Just the tablets and you know when you can have either infarct or something. You can have a stroke; you can have everything from hypertension" (3)

"It's just too scary and I think the bit that scared me the most was I was asymptomatic - I don't feel anything" (11)

Most women also reacted by expressing guilt and questioned themselves. For example:

"Why did it happen to me? Could I have done something to prevent it?" (6) 
"I've been questioning myself. I say why you have preeclampsia? Why your blood pressure is a problem? I think I have to change the way I'm living" (20) A few women were disappointed with the subsequent loss of control over the situation. They said:

"I felt like I didn't have a voice and I didn't know what was going to happen to me so it was really nerve-racking" (15)

"I was pretty emotional because I couldn't control my own body. I felt betrayed by my own body because I couldn't do anything" (8)

Many women reacted to the sense of urgency once the diagnosis was given. Some examples were:

"They said 'You're going to have your baby tomorrow'. So I didn't really have time to think about how that changed things, it was just rush, rush, rush" (1) "She just went through the procedure with me, told me everything that would happen and then took me around straight away and they broke my waters straight away. So, I didn't really have long to think about it. It was just bang, bang, bang" (14) DELETE THIS QUOTE

"I think all of a sudden people were a lot more concerned. It very quickly changed everything" (5)

Once a diagnosis of GH or PE had been given, women reacted by feeling scared, surprised, guilty, with a loss of control of the situation. Women also felt a sense of urgency regarding the birth.

\section{Challenges of being a mother}

Becoming and being a mother was challenging. These challenges began from the time of diagnosis and continued months after the birth.

All women worried about the health of their baby, what a preterm birth would involve and how this would affect their mothering. They said: 
"I was thinking as long as he grows up fine, he comes out alive and kicking and there's no problems, that's all I been thinking of. I'm not thinking about myself" (3)

"I was worried about him. I was not worried about my own wellbeing. I think I just assumed that I would be OK and it was all about getting him delivered" (7) Some women worried about not surviving and not being around for their baby. Some of the more dramatic examples included:

"I'm a little bit worried if my blood pressure is high or if something happen, if it too high I can die" (19)

"It crosses my mind that if I won't be around, who will take care of them? It's a scary thought - I just try not to dwell on that part" (11)

Those women who needed care in an acute care setting felt that they missed the birth or early parenting experience because of loss of recall and/or physical separation from the baby. For example, women who spent time in ICU at one hospital while their baby was transferred to another commented:

"I saw her one week later when I came out of the coma. I think initially when I came out I hadn't even realised that I had given birth" (6)

"I got my partner to take a photo when he went over but I would have rather seen her properly" (16)

"My husband went to see him every day and he brought the photos to me. I even can't see his face in all the photos because he has all the CPAP and tubes" (20)

Some women voiced the challenges of being a mother and forming a bond with their baby after the birth. One woman said:

“Being away from her, it's not an easy thing you know. You think you've got another two months to prepare before she comes home and all of a sudden she's here and yet she's nowhere to be seen" (6)

"It just didn't feel real. It was like l'd had her but It was like going to visit someone else's child in a way. I just didn't get that bond........ couldn't stop 
thinking about her, but I just felt that the connection wasn't there and that obviously made me even more sad" (6)

Some described how seeing, touching, holding and feeding their baby helped them cope with the separation and isolation from the baby, and be a mother. They said:

"They got to bring him up to me in HDU, so he came up twice which was really nice" (7)

"I insisted on breastfeeding so every three hours I got a visit which made me happy. I wasn't so isolated from her then" (8)

The few women who were discharged from hospital care while their baby remained in a nursery disclosed sadness, emptiness and worry. These women were upset sharing this part of their story, expressing the challenges that they faced as a new mother. Some examples include:

"It was really horrible. That was really, really hard. I knew it was going to be hard but I didn't think it would be that hard. I was very afraid that he wouldn't be OK left in the hospital which is strange because you think he was around all the nurses and doctors and everyone's looking after him, but I think I just felt very worried that I was leaving him behind" (7)

"I still felt short changed that I didn't get to take my baby home. My head knew why it couldn't happen, but I still wished it could" (16)

"I just feel so sorry for him; I have to leave him there" (20)

Women described several challenges they faced while trying to be a mother to their baby. These challenges were more evident in those who had a preterm baby or were physically separated.

\section{Processing and accepting the situation}

Processing and accepting the situation took time. Women needed time to appreciate the seriousness of the problem and the effect that hypertension had on their pregnancy and birth plans.

Despite the urgency of the situation, they needed time to process the information at the time of diagnosis. For example: 
"Ok, just take a few steps back now and let me digest" (9)

"I can't process that, I don't want to know yet. And then I remember thinking well what exactly does this mean?" (16)

Most women accepted the situation as they felt that it was out of their control and they couldn't change things. They said:

“It just happened. Just deal with it.......you can't do anything about it; you can't change what is going to happen" (2)

"It was a case of well if that's what it is, then that's what it is" (17)

Some expressed disappointment that the birth did not go as planned but they accepted that the plan had to change. They said:

"I wanted to have a water birth with no intervention, so I was a bit disappointed in that but you know, stuff happens, you can't really change it" (14)

"I didn't have a choice. That upset me more than anything, having the caesarean. At the same time, the baby's first so it was more like, get her out, do whatever you have to do" (15)

Some women said they were busy focussing on what was going on, caring for or visiting the baby and did not accept the seriousness until both were home. Their processing and acceptance came later. For example:

“You don't realise until you're well past that point, just how hard and stressful it was. You just get on with it at the time. That's just what you've got to do" (16)

"I don't think I dwelled on it too much. It was more like that happened and I have to push on with caring for a child and learning how to do that" (10)

Processing and acceptance sometimes occurred months later, for example:

"Afterwards when I think about it, I think gee, that was pretty scary and I was a lot sicker than I thought or wanted to admit to myself at the time. I don't like thinking about it too much because it still makes me feel anxious" (7) 
"I didn't really deal with it till at least six months afterwards and that's when I really started to think about the birth and how it could have been better. So it was all about learning to let go" (8)

Processing and accepting the situation occurred at different times for different women, and took up to many months depending on the severity of the disorder and the situation.

\section{'Moving on' from the experience}

Moving on from the experience meant that women expressed relief and felt that everything was going to be all right. The time taken for women to reach this stage varied. Some 'moved on' when they felt the experience was over saying:

"I'm glad that she's finally here. You been waiting for months and months and then finally she's here and just not thinking about not having that fear any more that we're both at risk. I was really relieved about that" (4)

"I was so relieved and happy that we were both OK that she was OK and I was OK and everything was going to be OK. I just felt like everyone was going to be OK. I was so grateful that when she came out she was, as we said, underdone but perfect" (16)

Staying in hospital for longer than expected slowed down women's ability to 'move on'. Once they had given birth and felt well, they wanted to go home to start their lives with their babies. Most accepted that even though they felt well, they were still at risk. They said:

"I was feeling fine on the second day but they said they wanted to keep me there just to be on the safe side and I'm like, 'Oh OK then but I feel fine'. If I could have, I would have liked to come home a bit earlier but they had to keep me in because of what happened" (9)

"I just wanted to come home, just bring him home and get out of the hospital and start our life with him' (2)

'Moving on' also meant thinking about the next pregnancy. Recognising that HDP could recur made some feel anxious. Others felt comfortable that a next pregnancy 
would be monitored closely and they would be more informed of signs to be aware of, so considered another pregnancy. For example:

"I just decide to have one baby. I'm not sure if another, next pregnancy, what's going on. I have to save my life for my daughter" (19)

"The doctor said I'll be closely monitored the second time around just in case it does happen again. So, hopefully......fingers crossed" (9)

"I know what to look for and I'm a bit more informed this time so that's OK.

They said that l'd need to see a renal physician next time I get pregnant so I'll be a bit more prepared for it I guess. It hasn't put me off having another baby" (18)

A strong theme was that women were ready to 'move on' at different times following the birth. This was evident through their desire to leave the hospital and discussing a subsequent pregnancy. The motivation for 'moving on' was often that the birth was over and it was time for her to care for her baby.

\section{Mediating Factors}

Throughout the interviews, women described mediating factors that helped them cope with the situation: Feeling safe and trusting the care providers, Having continuity of care and carer and Valuing support from family and friends.

Feeling safe and trusting the care providers.

All women felt safe in hospital and felt it was the best place for them to be. For example:

"I'm all right in the hospital. Nothing to worry about because if I'm home alone and something happen, it's more worry. I be OK there with doctors and midwives. In the hospital I was just confident with the doctor and midwife" (19) "When they told me about what's going to happen I think I'm in the hospital and in the right place" (20)

"Then I need to stay in hospital because that's the safest place for me to be" (16) 
Feeling informed about their progress and being included in decision making helped women feel safe. For example:

"They [midwives] put you at ease and they tell you each time they take your blood pressure how it's going" (10)

"They were always looking after me and letting me know each step of the way what was happening. I was really happy with that" (8)

Most women felt that the midwives and doctors were experts and they were 'in good hands'. They were less worried, anxious and concerned because they trusted these experts, saying:

"I found it a bit comforting knowing that I was in such a scary position and she [midwife] was very experienced in doing what she does so that's good to know" (12)

“You have to trust whoever's looking after you cause they will be the one who will help you at the end or if anything goes wrong" (3)

Women felt confident that they were safe after forming a relationship with staff, trusting them and viewing them as experts. Feeling informed also contributed to them feeling safe.

Having continuity of care and carer

Continuity of care and carer was important to the women as their carers knew them and their history. For example:

"When everything was normal you just go there [antenatal clinic] wait to see whoever will look after you. But after they found I had the hypertension and they put me on the medication, I think I got good continuous care from one or two person" (3)

"It was nice to have one familiar face who knew my story and my case in the Delivery Suite" (2)

Being cared for by someone they knew and trusted helped them feel more comfortable and supported: 
"Labour wasn't that bad and I had one of the educators with me the whole time. No midwives swapped and changed on me or anything. So everything went really smoothly. I think I was pretty lucky" (5)

"She [the doctor] was there pretty much every day and I remember saying to her it was really lovely to see her everyday cause it was a familiar face consistently. She was obviously busy but she took time to explain and answer any questions. So that was good' (16)

Women enjoyed participating in the 'continuity of care experience,' as part of the clinical experience of midwifery students. They said:

"I actually had a trainee midwife with me so that made it a lot easier actually. It was good" (5)

"I had a student midwife with me the whole time that I was there. She was a tremendous support. So, being with her, I didn't really have any concerns at all. I was a bit nervous about the whole birth experience but she made it a whole lot better than what it would have been otherwise" (14)

Women described how they felt well supported and their experience was improved though having continuity of care and carer.

Valuing social support from partner, family and friends

Support from partner, family and friends was important in helping them recover. Some women felt like they needed more support during the hospital stay and hospital rules were too restrictive to facilitate this. For example:

"I was talking a lot to friends and they were giving me a lot of support but it's so different over the phone or through text. You just want human contact. I know there's a period where no one's allowed to come into the hospital at night time with you, but I think that's when you do most of your thinking" (8) "So the support that I had from those two [partner and mother] was just incredible. I couldn't have done it without them" (16)

Support was especially important for women with preterm babies in hospital. One woman said: 
"I guess you could call it a traumatic experience in that it's not the norm, and it was fairly dramatic, but I don't feel like I've been left to flounder and a lot, a large part of this is because of the partner and mother I have. I'm very aware and very grateful for both of them" (16)

Having social support was a dominant theme. Women expressed that this support was necessary throughout the experience but was sometimes hampered by hospital rules.

\section{DISCUSSION}

This study aimed to gain insight into women's experience of having GH or PE and report on mediating factors. The study provides a unique opportunity to understand the HDP experience from the woman's viewpoint, an area that currently lacks research. Such insights may help inform practice to improve the woman's experience and facilitate her coping strategies (Coster-Schulz \& Mackey 1998). In this study, the women described the challenges they faced when informed of the diagnosis, having the baby, being separated from their baby and 'moving on' from the experience. Feeling safe, having continuity of care and carer and support were identified as being important to the women.

Other studies have also shown that the separation of mother and baby is challenging for women adapting to being a mother (Engstrom \& Lindberg 2011). These challenges may not be due to the $\mathrm{GH}$ or $\mathrm{PE}$, rather the physical separation, especially if the woman is in an ICU. Social support was reported as being important for the women by Engstrom and Lindberg (2011) which is in line with our study. Support from family members, friends, and health professionals is particularly important for women at risk of preterm birth (Hodnett, Fredericks \& Weston 2010). It has also been reported as being important for the development of maternal-fetal attachment (Yarcheski et al. 2009). In our study, it was evident that strategies such as flexibility in hospital visiting hours would help with the support available from family and friends while continuity of care would improve support from care providers.

Midwifery continuity of care has long been identified as being beneficial for women throughout pregnancy and childbirth (Homer, Davis, et al. 2002; Sandall et al. 2016; 
Tracy et al. 2013). Women who experience HDP require collaborative care from obstetric, medical and midwifery teams. Continuity of care from such a collaborative team is important and beneficial for women with a high risk pregnancy (Biro et al. 2003; Bradshaw, Lewis \& Steer 1995; Homer, Farrell, et al. 2002). Increased satisfaction with the birth experience has been reported by women with a complicated pregnancy who are cared for by a multidisciplinary team (Biro et al. 2003; Bradshaw, Lewis \& Steer 1995), and women with a pregnancy risk also reported less worry in an earlier study (Homer, Farrell, et al. 2002). Women participating in our study described continuity of care as being helpful in improving their birth experience. Hence, care of women with a high risk pregnancy should be provided through a multidisciplinary, collaborative, continuity of care model. This model is realistically achievable in a tertiary obstetric referral service (Biro et al. 2003; Tracy et al. 2013).

Previous studies reporting on women's perspectives of their experience of a complicated pregnancy have focussed on the hospital admission and the postpartum period, usually only days or weeks. This study presents a comprehensive exploration of the woman's experience with GH or PE, from diagnosis to the first year after the birth. Our analysis has shown that women take time to realistically reflect on their experience and process what happened.

Our study has explored the birth experience for women who experienced GH or PE. This is the first time such a specific study has been undertaken. All women interviewed for this study had their pregnancy care at one hospital. This hospital has a multidisciplinary collaborative team whose focus is caring for women with HDP using firm evidence based policies and practice. This continuity of care model may have positively influenced the women's experience in this study.

The limitations to this study include that all women who participated had their pregnancy care at St George Hospital in Sydney. Accordingly, the majority of women reported on their experience of the less severe forms of $\mathrm{GH}$ or PE from a diverse range of gestational ages. All women in this study gave birth at greater than 30 weeks gestation. It is not clear whether women with earlier gestations would feel the same or if the experiences in other hospitals or other countries would be different. 


\section{CONCLUSIONS}

Women have profound experiences after the diagnosis of GH or PE. They face challenges from the time of diagnosis through to many months after the birth of their baby. Their pregnancy, birth and postnatal care influences their experience, how they cope with the situation, and their mothering pathways. The implications of the findings for midwifery practice include having access to appropriate multidisciplinary continuity models of care that includes care from a known midwife and facilitating social support for these women.

This research did not receive any specific grant from funding agencies in the public, commercial, or not-for-profit sectors.

All authors declare that there are no actual or potential conflicts of interest. 
Figure 1: Women's experiences of havng either gestational hypertension or preeclampsia.

1. Reacting to

the diagnosis

- feeling surprised and scared

- Losing control

- Sensing urgency

-Emotional hardships
2. Challenges of
being a mother
the event
$\begin{aligned} & \text {-Physical separation } \\ & \text {-fearing not bonding with their baby, coping with the separation }\end{aligned}$

3. Processing

and accepting

what happened

- Needing time

-Realising the seriousness of the situation

\section{4. 'Moving on' \\ from the \\ experience}

-Thinking about the next pregnancy

\section{FEELING SAFE AND TRUSTING CARE PROVIDERS}

HAVING CONTINUITY OF CARE

VALUING SOCIAL SUPPORT FROM PARTNER, FAMILY AND FRIENDS 
Table 1. Demographics of women interviewed

\begin{tabular}{|c|c|c|c|c|c|c|c|c|c|}
\hline ID & Age & Ethnicity & Parity & Diagnosis & $\begin{array}{l}\text { History } \\
\text { of HDP }\end{array}$ & $\begin{array}{l}\text { Postpartum } \\
\text { ICU admission }\end{array}$ & $\begin{array}{l}\text { Gestation at } \\
\text { birth (weeks) }\end{array}$ & $\begin{array}{l}\text { Birth Weight } \\
\text { (grams) }\end{array}$ & $\begin{array}{l}\text { Days in } \\
\text { SCN/NICU }\end{array}$ \\
\hline 1 & $30-35$ & Caucasian & $M$ & $\mathrm{PE}$ & $\mathrm{GH}$ & no & $34-36$ & 2720 & 0 \\
\hline 2 & $25-30$ & Caucasian & $\mathrm{P}$ & $\mathrm{PE}$ & $\mathrm{N} / \mathrm{A}$ & yes & $34-36$ & 2960 & $1-7$ \\
\hline 3 & $25-30$ & Asian & $\mathrm{P}$ & $\mathrm{PE}$ & $\mathrm{N} / \mathrm{A}$ & no & $34-36$ & 2020 & $7-14$ \\
\hline 4 & $35-40$ & Asian & $\mathrm{P}$ & $\mathrm{PE}$ & $\mathrm{N} / \mathrm{A}$ & no & $37-40$ & 2670 & 0 \\
\hline 5 & $20-25$ & Caucasian & $\mathrm{P}$ & $\mathrm{PE}$ & $\mathrm{N} / \mathrm{A}$ & no & $37-40$ & 2830 & 0 \\
\hline 6 & $35-40$ & Other & $\mathrm{M}$ & $\mathrm{PE}$ & No & yes & $30-33$ & 1520 & $>28$ \\
\hline 7 & $25-30$ & Other & $\mathrm{P}$ & $\mathrm{PE}$ & $\mathrm{N} / \mathrm{A}$ & no & $37-40$ & 3250 & 0 \\
\hline 8 & $20-25$ & Other & $\mathrm{P}$ & $\mathrm{PE}$ & $\mathrm{N} / \mathrm{A}$ & no & $37-40$ & 2915 & $1-7$ \\
\hline 9 & $30-35$ & Other & $\mathrm{P}$ & $\mathrm{PE}$ & $\mathrm{N} / \mathrm{A}$ & yes & $40-42$ & 3720 & $1-7$ \\
\hline 10 & $30-35$ & Caucasian & $\mathrm{P}$ & $\mathrm{GH}$ & $\mathrm{N} / \mathrm{A}$ & no & $37-40$ & 3360 & 0 \\
\hline 11 & $30-35$ & Asian & $\mathrm{M}$ & $\mathrm{PE}$ & $\mathrm{PE}$ & no & $37-40$ & 2640 & 0 \\
\hline 12 & $20-25$ & Caucasian & $\mathrm{P}$ & $\mathrm{PE}$ & $\mathrm{N} / \mathrm{A}$ & no & $37-40$ & 3350 & 0 \\
\hline 13 & $30-35$ & Asian & $\mathrm{M}$ & $\mathrm{PE}$ & No & no & $37-40$ & 2680 & 0 \\
\hline 15 & $30-35$ & Caucasian & $\mathrm{M}$ & $\mathrm{GH}$ & No & no & $37-40$ & 4140 & 0 \\
\hline 16 & $30-35$ & Caucasian & $\mathrm{P}$ & $\mathrm{PE}$ & $\mathrm{N} / \mathrm{A}$ & no & $30-33$ & 1350 & $>28$ \\
\hline 17 & $30-35$ & Caucasian & $\mathrm{P}$ & PE & $\mathrm{N} / \mathrm{A}$ & no & $37-40$ & 3405 & $1-7$ \\
\hline 18 & $30-35$ & Caucasian & $\mathrm{P}$ & PE & $\mathrm{N} / \mathrm{A}$ & no & $37-40$ & 2630 & 0 \\
\hline 19 & $35-40$ & Asian & $\mathrm{P}$ & PE & $\mathrm{N} / \mathrm{A}$ & no & $34-36$ & 2470 & $1-7$ \\
\hline 20 & $30-35$ & Asian & $\mathrm{P}$ & PE & $\mathrm{N} / \mathrm{A}$ & no & $30-33$ & 1775 & $>28$ \\
\hline
\end{tabular}

Note: Only ranges are provided for age, gestation and days in NICU/ICU to protect anonymity

$\mathrm{M}=$ multiparous

$\mathrm{P}=$ primiparous

PE=preeclampsia

$\mathrm{GH}=$ gestational hypertension

ICU=Intensive Care Unit

$\mathrm{SCN}=$ Special Care Nursery

NICU=Neonatal Intensive Care Unit 


\section{REFERENCES}

American College of Obstetricians and Gynecologists 2013, Hypertension in Pregnancy, Washington, DC.

Andersgaard, A.B., Acharya, G., Mathiesen, E.B., Johnsen, S.H., Straume, B. \& Oian, P. 2012, 'Recurrence and long-term maternal health risks of hypertensive disorders of pregnancy: a population-based study', American Journal of Obstetrics \& Gynecology, vol. 206, no. 2, pp. 143.e1-8.

Anderson, C.M. 2007, 'Preeclampsia: exposing future cardiovascular risk in mothers and their children', Journal of Obstetric, Gynecologic, \& Neonatal Nursing: Clinical Scholarship for the Care of Women, Childbearing Families, \& Newborns, vol. 36, no. 1, pp. 3-8.

Avis, M. 2003, 'Do we need methodological theory to do qualitative research?', Qualitative Health Research, vol. 13, pp. 995-1004.

Barlow, J., Hainsworth, J. \& Thornton, S. 2008, 'Women's experience of hospitalisation with hypertension during pregnancy: feeling a fraud', Journal of Reproductive and Infant Psychology, vol. 26, no. 3, pp. 157-67.

Bellamy, L., Casas, J.-P., Hingorani, A. \& Williams, D. 2007, 'Pre-eclampsia and risk of cardiovascular disease and cancer in later life: systematic review and meta-analysis', British Medical Journal, vol. 335, p. 974.

Bennett, A. 1985, 'The birth of a first child: Do women's reports change over time?', Birth, vol. 13, no. 3, pp. 153-8.

Biro, M., Waldenstrom, U., Brown, S. \& Pannifex, J. 2003, 'Satisfaction with team midwifery care for low- and high-risk women: a randomized controlled trial', Birth, vol. 30, no. 1, pp. 1-10.

Bradshaw, C., Lewis, P. \& Steer, P. 1995, 'A midwifery team for high-risk pregnancies', Modern Midwife, vol. 5, no. 5, pp. 26-9.

Braun, V. \& Clarke, V. 2006, 'Using thematic analysis in psychology', Qualitative Research Psychology, vol. 3, pp. 77-101.

Brown, M., Bell, R., Collins, C., Waring, G., Robson, S., Waugh, J. \& Finch, T. 2013, 'Women's perspective of future risk following pregnancies complicated by preeclampsia', Hypertension in Pregnancy, vol. 32, no. 1, pp. 60-73.

Bushnell, C. \& Chireau, M. 2011, 'Preeclampsia and stroke: risks during and after pregnancy', Stroke Research and Treatment, vol. 2011, p. 858134.

Centre for Epidemiology and Evidence 2016, New South Wales Mothers and Babies 2014, Sydney.

Coster-Schulz, M. \& Mackey, M. 1998, 'The perterm labour experience: A balancing act.', Clinical Nursing Research, vol. 7, no. 4, pp. 335-59.

Davis, G., Roberts, L., Mangos, G., Henry, A., Pettit, F., O'Sullivan, A., Homer, C., Craig, M., Harvey, S. \& Brown, M. 2016, 'Postpartum physiology, psychology and paediatric follow up study (P4 Study) - Study protocol', Pregnancy Hypertension: An International Journal of Women's Cardiovascular Health, vol. in press.

Engstrom, A. \& Lindberg, I. 2011, 'Mothers' experiences of a stay in an ICU after a complicated childbirth', Nursing in Critical Care, vol. 17, no. 2, pp. 64-70.

Furuta, M., Sandall, J. \& Bick, D. 2014, 'Women's perseptions and experiences of severe maternal morbidity-A synthesis of qualitative studies using a meta-ethnographic approach', Midwifery, vol. 30, pp. 158-69.

Giguere, Y., Charland, M., Theriault, S., Bujold, E., Laroche, M., Rousseau, F., Lafond, J. \& Forest, J.C. 2012, 'Linking preeclampsia and cardiovascular disease later in life', Clinical Chemistry \& Laboratory Medicine, vol. 50, no. 6, pp. 985-93.

Hodnett, E., Fredericks, S. \& Weston, J. 2010, 'Support during pregnancy for women at increased risk of low birthweight babies', Cochrane Database of Systematic Reviews.

Homer, C., Davis, G., Cooke, M. \& Barclay, L. 2002, 'Women's experineces of continuity of midwifery care in a randomised controlled trial in Australia', Midwifery, vol. 18, pp. 102-12. 
Homer, C., Farrell, T., Davis, G. \& Brown, M. 2002, 'Women's worry in the antenatal period', British Journal of Midwifery, vol. 10, no. 6, pp. 356-60.

McDonald, S., Malinowski, A., Zhou, Q., Yusuf, S. \& Devereaux, P. 2008, 'Cardiovascular sequelae of preeclampsia/eclampsia: a systematic review and meta-analyses.', American Heart Journal, vol. 156, pp. 918-30.

QSR International 2014, 'NVIVO10 for Windows. Getting Started', QSR International Pty Ltd.

Roberts, J.M. \& Gammill, H. 2005, 'Pre-eclampsia and cardiovascular disease in later life', Lancet, vol. 366, no. 9490, pp. 961-2.

Saldana, J. 2013, The Coding Manual for Qualitative Researchers. Second Edition., SAGE Publications Ltd, London.

Sandall, J., Soltani, H., Gates, S., Shennan, A. \& Devane, D. 2016, 'Midwife-led continuity models versus other models of care for childbearing women', Cochrane Database of Systematic Reviews.

Sandelowski, M. 2000, 'Whatever happened to qualitative description?', Research in Nursing and Health, vol. 23, pp. 334-40.

Sharp, D., Hay, D., Pawlby, S., Schumucker, G., Allen, H. \& Kumar, R. 1995, 'The impact of postnatal depression on boys' intellectual development', Journal of Child Psychology and Psychiatry, vol. 36 , no. $1315-1336$.

Simkin, P. 1992, 'Just another day in a woman's life? Part II: Nature and consistency of women's long-term memories of their first birth eperience', Birth, vol. 19, no. 2, pp. 64-81.

Steegers, E., von Dadelszen, P., Duvekot, J. \& Pijnenborg, R. 2010, 'Pre-eclampsia', Lancet, vol. 21, no. 376, pp. 631-44.

Tracy, S., Hartz, D., Tracy, M., Kildea, S., Allen, Y., Forti, A., Hall, B., Lainchbury, A., Stapleton, H., Beckmann, M., Bisits, A., Homer, C., Foureur, M., White, J. \& Welsh, A. 2013, 'Caseload midwifery care for women of all risk compared to standard hospital care: a randomized controlled trial. (Midwives @ New Group practice Options: M@NGO trial.)', Lancet, vol. 382, no. 9906, pp. 1723-32.

Tranquilli, A., Dekker, G., Magee, L., Roberts, J., Sibai, B., Steyn, W., Zeeman, G. \& Brown, M. 2014, 'The classification, diagnosis and management of the hypertensive disorders of pregnancy: A revised statement from the ISSHP', Pregnancy Hypertension, vol. 4, no. 2, pp. 97-104.

Vaismororadi, M., Turunen, H. \& Bondas, T. 2013, 'Content analysis and thematic analysis: Implications for conducting a qualitative desriptive study', Nursing and Health Sciences, vol. 15, pp. 398-405.

Vincent, C. 2006, Patient Safety, Churchhill Livingstone, New York.

Williams, D. 2011, 'Long-term complications of preeclampsia', Seminars in Nephrology, vol. 31, no. 1, pp. 111-22.

Yarcheski, A., Mahon, N., Yarcheski, T., Hanks, M. \& Cannella, B. 2009, 'A meta-analytic study of predictors of maternal-fetal attachment', International Journal of Nursing Studies, vol. 46, no. 5 , pp. 708-15. 


\section{Consolidated criteria for reporting qualitative studies (COREQ): $32-$ item checklist}

\begin{tabular}{|c|c|c|}
\hline No. Item & Guide questions/description & $\begin{array}{l}\text { Reported in } \\
\text { Section }\end{array}$ \\
\hline \multicolumn{3}{|l|}{$\begin{array}{l}\text { Domain 1: Research team } \\
\text { and reflexivity }\end{array}$} \\
\hline \multicolumn{3}{|l|}{ Personal Characteristics } \\
\hline 1. Inter viewer/facilitator & $\begin{array}{l}\text { Which author/s conducted the interview or } \\
\text { focus group? }\end{array}$ & $\begin{array}{l}\text { METHODS. Data } \\
\text { collection. pp } 4 .\end{array}$ \\
\hline 2. Credentials & What were the researcher's credentials? & $\begin{array}{l}\text { METHODS. Data } \\
\text { collection. pp } 4 .\end{array}$ \\
\hline 3. Occupation & $\begin{array}{l}\text { What was their occupation at the time of } \\
\text { the study? }\end{array}$ & $\begin{array}{l}\text { METHODS. Data } \\
\text { collection. pp } 4 .\end{array}$ \\
\hline 4. Gender & Was the researcher male or female? & $\begin{array}{l}\text { METHODS. Data } \\
\text { collection. pp } 4 .\end{array}$ \\
\hline 5. Experience and training & $\begin{array}{l}\text { What experience or training did the } \\
\text { researcher have? }\end{array}$ & $\begin{array}{l}\text { METHODS. Data } \\
\text { collection. pp } 4 . \\
\end{array}$ \\
\hline \multicolumn{3}{|l|}{ Relationship with participants } \\
\hline 6. Relationship established & $\begin{array}{l}\text { Was a relationship established prior to } \\
\text { study commencement? }\end{array}$ & $\begin{array}{l}\text { METHODS. } \\
\text { Participants. pp } 4 .\end{array}$ \\
\hline $\begin{array}{l}\text { 7. Participant knowledge of } \\
\text { the interviewer }\end{array}$ & $\begin{array}{l}\text { What did the participants know about the } \\
\text { researcher? e.g. personal goals, reasons } \\
\text { for doing the research }\end{array}$ & $\begin{array}{l}\text { METHODS. } \\
\text { Participants. pp } 4 .\end{array}$ \\
\hline 8. Interviewer characteristics & $\begin{array}{l}\text { What characteristics were reported about } \\
\text { the interviewer/facilitator? e.g. Bias, } \\
\text { assumptions, reasons and interests in the } \\
\text { research topic }\end{array}$ & $\begin{array}{l}\text { METHODS. } \\
\text { Participants. pp4. }\end{array}$ \\
\hline \multicolumn{3}{|l|}{ Domain 2: study design } \\
\hline \multicolumn{3}{|l|}{ Theoretical framework } \\
\hline $\begin{array}{l}\text { 9. Methodological orientation } \\
\text { and Theory }\end{array}$ & $\begin{array}{l}\text { What methodological orientation was } \\
\text { stated to underpin the study? e.g. } \\
\text { grounded theory, discourse analysis, } \\
\text { ethnography, phenomenology, content } \\
\text { analysis }\end{array}$ & METHODS. pp 3. \\
\hline \multicolumn{3}{|l|}{ Participant selection } \\
\hline 10. Sampling & $\begin{array}{l}\text { How were participants selected? e.g. } \\
\text { purposive, convenience, consecutive, } \\
\text { snowball }\end{array}$ & $\begin{array}{l}\text { METHODS. } \\
\text { Participants. pp } 4 .\end{array}$ \\
\hline 11. Method of approach & $\begin{array}{l}\text { How were participants approached? e.g. } \\
\text { face-to-face, telephone, mail, email }\end{array}$ & \begin{tabular}{|l|} 
METHODS. \\
Participants. pp 4.
\end{tabular} \\
\hline 12. Sample size & How many participants were in the study? & $\begin{array}{l}\text { METHODS. } \\
\text { Participants. pp } 4 .\end{array}$ \\
\hline 13. Non-participation & $\begin{array}{l}\text { How many people refused to participate or } \\
\text { dropped out? Reasons? }\end{array}$ & \begin{tabular}{|l|} 
METHODS. \\
Participants. pp 4.
\end{tabular} \\
\hline \multicolumn{3}{|l|}{ Setting } \\
\hline 14. Setting of data collection & $\begin{array}{l}\text { Where was the data collected? e.g. home, } \\
\text { clinic, workplace }\end{array}$ & $\begin{array}{l}\text { METHODS. Data } \\
\text { collection. pp } 4 . \\
\end{array}$ \\
\hline $\begin{array}{l}\text { 15. Presence of non- } \\
\text { participants }\end{array}$ & $\begin{array}{l}\text { Was anyone else present besides the } \\
\text { participants and researchers? }\end{array}$ & No \\
\hline 16. Description of sample & What are the important characteristics of & FINDINGS. pp 6. \\
\hline
\end{tabular}




\begin{tabular}{|c|c|c|}
\hline & the sample? e.g. demographic data, date & Table 1. pp 20 \\
\hline \multicolumn{3}{|l|}{ Data collection } \\
\hline 17. Interview guide & $\begin{array}{l}\text { Were questions, prompts, guides provided } \\
\text { by the authors? Was it pilot tested? }\end{array}$ & $\begin{array}{l}\text { METHODS. Data } \\
\text { collection. pp } 4 .\end{array}$ \\
\hline 18. Repeat interviews & $\begin{array}{l}\text { Were repeat interviews carried out? If yes, } \\
\text { how many? }\end{array}$ & No \\
\hline 19. Audio/visual recording & $\begin{array}{l}\text { Did the research use audio or visual } \\
\text { recording to collect the data? }\end{array}$ & $\begin{array}{l}\text { METHODS. Data } \\
\text { collection. pp } 5 .\end{array}$ \\
\hline 20. Field notes & $\begin{array}{l}\text { Were field notes made during and/or after } \\
\text { the interview or focus group? }\end{array}$ & No \\
\hline 21. Duration & $\begin{array}{l}\text { What was the duration of the interviews or } \\
\text { focus group? }\end{array}$ & $\begin{array}{l}\text { METHODS. Data } \\
\text { collection. pp } 4 .\end{array}$ \\
\hline 22. Data saturation & Was data saturation discussed? & $\begin{array}{l}\text { DISCUSSION. pp } \\
17 .\end{array}$ \\
\hline 23. Transcripts returned & $\begin{array}{l}\text { Were transcripts returned to participants } \\
\text { for comment and/or correction? }\end{array}$ & No \\
\hline \multicolumn{3}{|l|}{$\begin{array}{l}\text { Domain 3: analysis and } \\
\text { findings }\end{array}$} \\
\hline \multicolumn{3}{|l|}{ Data analysis } \\
\hline 24. Number of data coders & How many data coders coded the data? & $\begin{array}{l}\text { METHODS. Data } \\
\text { analysis. pp } 5 .\end{array}$ \\
\hline $\begin{array}{l}\text { 25. Description of the coding } \\
\text { tree }\end{array}$ & $\begin{array}{l}\text { Did authors provide a description of the } \\
\text { coding tree? }\end{array}$ & $\begin{array}{l}\text { METHODS. Data } \\
\text { analysis. pp } 5 .\end{array}$ \\
\hline 26. Derivation of themes & $\begin{array}{l}\text { Were themes identified in advance or } \\
\text { derived from the data? }\end{array}$ & $\begin{array}{l}\text { METHODS. Data } \\
\text { analysis. pp } 5 .\end{array}$ \\
\hline 27. Software & $\begin{array}{l}\text { What software, if applicable, was used to } \\
\text { manage the data? }\end{array}$ & $\begin{array}{l}\text { METHODS. Data } \\
\text { analysis. pp } 5 .\end{array}$ \\
\hline 28. Participant checking & $\begin{array}{l}\text { Did participants provide feedback on the } \\
\text { findings? }\end{array}$ & No \\
\hline \multicolumn{3}{|l|}{ Reporting } \\
\hline 29. Quotations presented & $\begin{array}{l}\text { Were participant quotations presented to } \\
\text { illustrate the themes/findings? Was each } \\
\text { quotation identified? e.g. participant } \\
\text { number }\end{array}$ & FINDINGS. pp 6-16. \\
\hline $\begin{array}{l}\text { 30. Data and findings } \\
\text { consistent }\end{array}$ & $\begin{array}{l}\text { Was there consistency between the data } \\
\text { presented and the findings? }\end{array}$ & FINDINGS. pp 6-16. \\
\hline 31. Clarity of major themes & $\begin{array}{l}\text { Were major themes clearly presented in } \\
\text { the findings? }\end{array}$ & FINDINGS. pp 6-16. \\
\hline 32. Clarity of minor themes & $\begin{array}{l}\text { Is there a description of diverse cases or } \\
\text { discussion of minor themes? }\end{array}$ & FINDINGS. pp 6-16. \\
\hline
\end{tabular}

